\title{
Commisioning Oily Water Separator System pada Kapal Bangunan Baru
}

\author{
Sulaiman*, Suharto \\ Program Studi D3 Teknologi Perancangan dan Konstruksi Kapal, Departemen Teknologi Industri, \\ Sekolah Vokasi Universitas Diponegoro \\ Jl. Prof. Soedarto, SH, Tembalang, Semarang, 50275 \\ *E-mail: sulaiman_naval@yahoo.com
}

Diterima: 18-08-2020; Direvisi: 05-12-2020; Dipublikasi: 28-12-2020

\begin{abstract}
Abstrak
Pada konvensi (Marine Pollution) MARPOL 73/78 Annex 1 untuk kapal tanker berukuran >150 GRT (selain dari kapal tanker berukuran > 400 GRT) dan Marpol Consolidate 2006 Annex 1 Regulation 32 "Oil/Water interface Detector" dan Regulation 34 "Control Of Dischare Of Oil” kamar mesin harus dilengkapi dengan sarana Oily water separator sebagai media pemisah antara air dan minyak. Tujuan artikel ini adalah untuk mengetahui permasalahan sehubungan dengan kendala pengoperasian Oily Water Separator. Metode pengumpulan data pada penulisan artikel ini studi literatur, wawancara, observasi, studipustaka. Hasil dari pemecahan permasalahan perawatan secara rutin perlu dilakukan untuk menjaga kuliatas dari performa mesin Oily Water Separator. Pengoperasian oleh operator kapal harus sesuai dengan standar operating procedure dengan baik dan benar. Selain itu pengecekan fungsi oil discharge monitoring pada sensor oil content meter perlu dilakukan agar pengaturan oil content meter yang sesuai dengan peraturan dari MARPOL Annex 1 yaitu sebesar15 ppm.
\end{abstract}

Kata kunci: Annex I; Commisioning; Kapal bangunan baru; Oil water separator

\begin{abstract}
At the Convention MARPOL 73/78 Annex 1 for tankers > 150 GRT (apart from tanker-sized > 400 GRT) and Marpol Consolidate 2006 Annex 1 Regulation 32 "Oil/Water interface Detector" and Regulation 34 "Control Of Dischare Of Oil" The engine must be equipped with a means of Oily water separator as a medium of separation between water and oil. The purpose of this article is to determine the problem with regards to operating constraints of Oily Water Separator. The methods of collecting data on this article are literary studies, interviews, observations, library studies. The result maintenance problem solving needs to be done to maintain a lecture of Oily Water Separator machine performance. Operation by the machine operator must conform to the operating procedure standards properly and correctly. In addition to checking the function of oil discharge monitoring on the sensor, the oil content meter needs to be done in order to set the oil content meter according to the regulations of MARPOL Annex 1 which is 15 ppm.
\end{abstract}

Keywords: Annex I; Commisioning; New building ship; Oil water separator

\section{Pendahuluan}

Menurut konvensi MARPOL 73/78 Annex 1 untuk kapal tanker berukuran >150 GRT (selain dari kapal tanker berukuran > 400 GRT) dan Marpol Consolidate 2006 Annex 1 Regulation 32 "Oil/Water interface Detector" dan Regulation 34 “Control Of Dischare Of Oil” kamar mesin harus dilengkapi dengan sarana Oily water separator sebagai media pemisah antara air dan minyak[1,2,3]. Persyaratan air got yang yang boleh di buang ke laut tidak melebihi dari 15 ppm dengan ketentuan kapal sedang dalam pelayaran, 12 mil dari daratan dan melihat arah angin dan arah arus yang tidak mengarah ke daratan, lihatgambar 1. Untuk kelancaran pengoperasian Oil water separator hendaknya di lakukan perawatan serta perbaikan secara berkala agar tidak mengganggu dalam pengoperasian kapal[3,4]. Salah satu penyebab terjadinya kinerja Oily water separator kurang optimal adalah kurangnya perawatan. Salah satu organisasi di dunia yaitu IMO telah menetapkan peraturan-peraturan yang berkenaan dengan prosedur dan tatacara pembuangan limbah kapal berikut sanksi bagi kapal yang melanggar sehingga untuk mendukung dan melaksanakan peraturan yang telah 
ditetapkan [5,6,7]. Observasi dalam sistem Oily Water Separator pada kapal bangunan baru, kapal ini merupakan kapal bangunan baru yang diprogramkan oleh pemerintah untuk Indonesia sebagai poros maritim dunia.

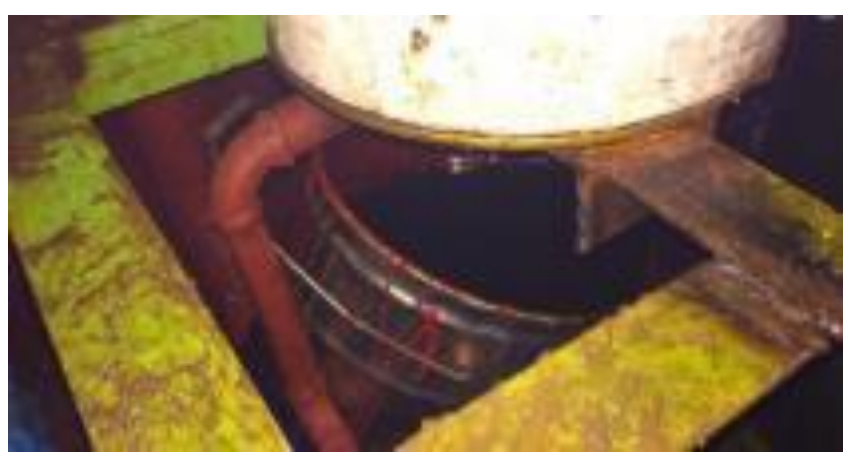

Gambar 1. Limbah pada got kapal

Oleh karena itu, dengan berkembangnya dunia maritim yang semakin maju dan bertambahnya jumlah kapal maka akan sangat mempengaruhi tingkat kepadatan alur transportasi laut berserta dengan pencemaran laut yang mungkin terjadi, akibat limbah-limbah yang dibuang dari kapal, terutama limbah yang mengandung minyak [8,9]. Tidak dapat dihindari bahwa setiap kapal pasti menghasilkan air got terutama di kamar mesin. Air got pada akhirnya akan di buang ke laut namun harus diperhatikan agar tidak terjadi pencemaran laut akibat dari pembuangan limbah tersebut $[3,6,9$, 10]. Dan mencegah sanksi yang dapat diberikan pada kapal yang melanggar dimana akan membawa kerugian bagi kapal dan perusahaan pelayaran, maka sekarang ini pada setiap kapal telah dilengkapi dengan peralatan atau mesin yang dapat membersihkan air got dari kandungan minyak Oily Water Separator (OWS) sehingga pada saat di buang ke laut tidak menimbulkan pencemaran $[2,9,11]$. Oily Water Separator (OWS) adalah mesin yang mampu memisahkan air dari air buangan yang mengandung minyak sampai hasil pemisahannya mencapai kurang dari 15 ppm. Fungsi OWS yaitu untuk memisahkan antara air dan kandungan minyak hingga mencapai maksimal 15 ppm, sehingga air buangan kelaut tidak menimbulkan pencemaran. Prinsip dasar dan cara kerja OWS yaitu pemisahannya berdasarkan berat jenis dari unsur-unsur yang terkandung di dalam air got $[12,13,14]$. Dimana unsur yang memiliki berat jenis paling besar (lumpur) akan berada paling bawah dan keluar lewat sludge out, kemudian air yang berat jenis lebih berat dari minyak dan lebih ringan dari lumpur akan berada dibawah minyak di ruang pemisah [15, 16, 17]. Sehingga minyak yang berada dipermukaan akan dialirkan ke Waste Oil Tank sedangakan air yang setelah melalui proses penyaringan yang kedua,akan keluar dari OWS dengan tingkat kandungan dibawah 15 ppm.Comisioning sendiri merupakan suatu istilah untuk pengujian terhadap suatu alat yang telah dipasang dan disetting untuk suatu sistem. Istilah Comisioning sama halnya dengan running in atau fungtion tes pada suatu kondisi permesinan. Biasanya kegiatan ini merupakan perbandingan dalam setelah dan sebelum dialakukan perbaikan atau service. Kendala permasalahan yang terjadi adalah mesin OWS ini seringkali tidak berfungsi secara optimal, hal itu terbukti dari volume perbandingan oli kotor yang dipisahkan dari air laut tersebut mengalami pernufunan fungsi dari record data penggunaan. Penurunan tersebut bernilai antara 3 - $8 \%$ terjadi karena pengoperasiannya yang tidak sesuai prosedur sehingga beban atau kinerja mesin untuk sementara diasumsikan mengalami ketimpangan dan tidak balance. Misalnya ketika pompa menyala maka sistem OWS secara otomatis harus siap untuk menjalankan mekanik rotarinya guna memfilter air yang bercampur oli akan tetapi terkadang OWS dioperasikan hanya ketika kondisi tangki sudah penuh dan harus disaring agar tidak tumpah atau memenuhi tangki. Hal ini yang menyebakan tekanan pada pipa suction menahan beban tekanan dari pompa. 
Sulaiman dkk./Jurnal Rekayasa Mesin

p-ISSN: 1411-6863, e-ISSN: 2540-7678

Vol.15|No.3|229-236|Desember|2020

Tujuan artikel ini adalah untuk mengetahui permasalahan sehubungan dengan kendala pengoperasian Oily Water Separator sehingga dapat mengetahui masalah utama dan penyebab yang terjadi pada perawatan mesin Oily water separator diatas kapal. Serta mencari pemecahan masalah dalam upaya menanggulangi berbagai penyebab permasalahan mesin Oily water separator yang mengacu kepada ketentuan MARPOL 73/78 Annex 1.

\section{Material dan metodologi}

Metode pengumpulan data pada penulisan artikel ini menggunakan beberapa tahap yaitu :

2.1. Studi literature membahas permasalahan dengan cara membaca literatur-literatur yang berhubungan dengan permasalahan yang akan dibahas

2.2. Wawancara yaitu dengan mengadakan tanya jawab, baik dengan departemen perencanaan, produksi maupun kepala proyek di di PT. Janata Marina Indah unit II Semarang. Hasil wawancara dengan ABK di kapal menjelaskan ketika ows dalam masa maintenance maka ada perubahan performa kemampuan dalam menyaring dari data record tiap mingguannya mengalami kenaikan dan penurunan secara dinamis, dapat dilihat pada Tabel 1.

Tabel 1.Performa OWS

\begin{tabular}{cccccc}
\hline Separator & Minggu 1 (mg/l) & Minggu 2 (mg/l) & Minggu 3 (mg/l) & $\begin{array}{c}\text { Rata-rata Oli yang } \\
\text { dipisahkan (mg/l) }\end{array}$ & $\begin{array}{c}\text { Jadwal } \\
\text { Maintenance }\end{array}$ \\
\hline A & 121 & 118 & 107 & 116 & 1 Bulan \\
B & 156 & 178 & 210 & 204 & 1 Bulan \\
C & 96 & 84 & 99 & 93 & 1 Bulan \\
A & 94 & 98 & 103 & 102 & 6 Bulan \\
B & 193 & 243 & 231 & 211 & 6 Bulan \\
C & 122 & 115 & 102 & 105 & 6 Bulan \\
A & 75 & 68 & 66 & 97 & 12 Bulan \\
B & 101 & 112 & 134 & 124 & 12 Bulan \\
C & 221 & 187 & 219 & 187 & 12 Bulan \\
\hline
\end{tabular}

2.3. Observasi yaitu dengan pengupulan data dilakukan dengan cara mencari pembanding yang memilikis pesifikasi yang hamper sama dengan tujuan sebagai koreksi terhadap hasil penulisan ini.

2.4. Studi Pustaka yaitu dengan mengumpulkan data yang berhubungan dengan penganalisaan dari buku yang berhubungan dengan permasalahan.

\section{Hasil dan pembahasan}

\subsection{Cara Kerja OWS}

Proses pemisahan pada tabung pertama yaitu tahap air got yang dipompa masuk ketabung pertama akan mengalami pemisahan dimana air got tersebut akan melewati plat-plat pemisah utama yang terpasang horizontal dalam tabung pemisah sehingga lumpur tidak akan melewati atau punikut dengan air got keruang pengumpul. Air got yang masih mengandung minyak yang melewati plat-plat utama ini akan menjalani proses pemisahan pada plat-plat kedua sehingga lumpur yang ringan akan tertahan. Selanjutnya dalam tabung ini akan terjadi proses pemisahan dimana prinsip kerjanya berdasarkan berat jenis cairan sehingga minyak yang memiliki berat jenis lebih rendah dari air akan berada dipermukaan air dan terkumpul dalam ruang pengumpulan minyak. Kemudian air got yang telah dipisahkan dengan minyak berdasarkan berat jenis ini, akan disalurkan ke tabung pemisah kedua. Kemudian proses pemisahan pada tabung kedua setelah melalui proses pemisahan pada tabung pemisah pertama, air got yang telah berkurang kandungan minyaknya akan mengalami proses pemisahan lagi, dimana pada tabung pemisah kedua air got akan disaring kembali 
Sulaiman dkk./Jurnal Rekayasa Mesin

p-ISSN: 1411-6863, e-ISSN: 2540-7678

Vol.15|No.3|229-236|Desember|2020

melalui Coallescer sehingga partikel-partikel minyak yang masih ikut dalam air got akan berkumpul didalam pengumpulan ruang minyak pada tabung kedua.

Air got yang telah dipisahkan dengan partikel-partikel minyak akan dialirkan keluar tabung pemisah untuk dibuang kelaut, namun sebelumnya melalui suatu alat pendeteksi kandungan minyak (Oil Content Meter) untuk mencegah terjadinya pencemaran di laut. Selanjutnya proses pengeluaran minyak dari ruang pengumpul pada tabung pemisah setelah mengalami proses pemisahan antara air got dan kandungan minyak dalam tabung, maka kandungan minyak yang terkumpul dalam ruang pengumpulan minyak akan terus bertambah selama pompa bilge masih bekerja. Hingga pada saat tingkat minyak dalam ruang sudah tinggi, maka alat pengontrol tingkat ketinggian minyak akan bekerja sehingga mengaktifkan katup solenoid untuk membuka. Maka pada saat itulah minyak yang terkumpul dalam ruang pengumpulan akan mengalir ke Waste Oil Tank, dengan adanya pengeluaran minyak dari dalam tabung, maka tingkat ketinggian minyak akan menurun kembali sehingga alat sensor akan mengaktifkan katup solenoid untuk menutup.

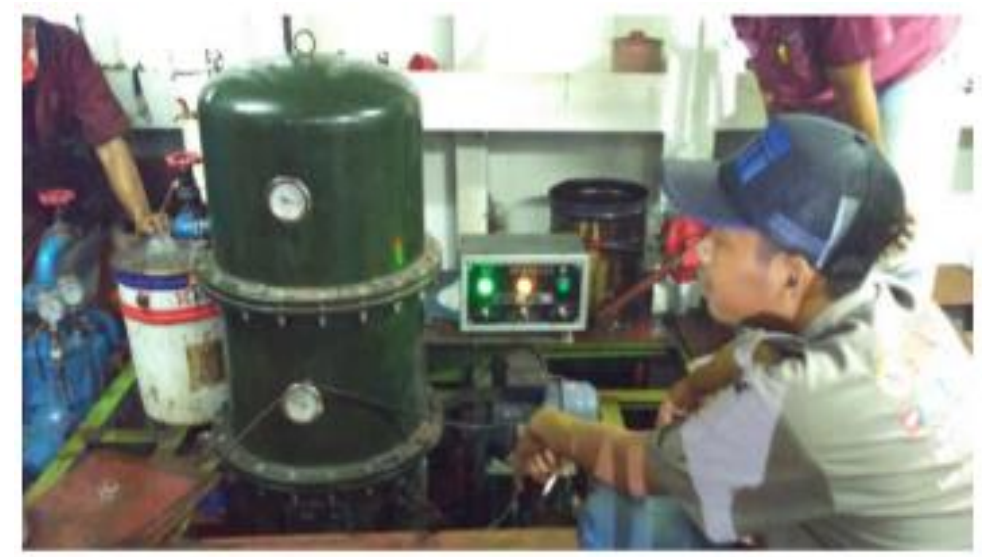

Gambar 2. Commissioning OWS System

\subsection{Langkah - langkah Pengoperasian OWS type CYF-1.OY}

\subsubsection{LangkahPersiapan}

a.Buka katup-katup yang terletakantarapompa got dan Oily Water Separator.

b.Tutup katup keluar sludge.

c. Buka katup yang terletak antara tabung pemisah pertama dan kedua.

d.Tutup katup yang terletak di atastabung (katup pengeluaran minyak) kedua.

e. Buka semua test cook pada tabung pemisah.

f. Buka katup manometer yang terpasang di atas tabung.

g.Buka katup yang terletak pada pipa pengeluaran air bersih.

h.Hidupkan switch Automatic Controller dan Oil Content Meter.

\subsubsection{Langkah Pemasukan Air}

a.Buka katup pengisapan air laut untuk pengisian air laut ke tabung.

b.Jalankanpompa got, saat air laut masuk ketabung, uadara dalam tabung akan keluar lewat Automatic Air Ventilation.

c.Periksa airlaut pada tabung dengan melihat Test Cock, aturtekanan air $0,5-0,7 \mathrm{~kg} / \mathrm{cm}^{2}$. Bila pada Test Cock air telah keluar, tutup test cock tabung pertama dan kedua. 
Sulaiman dkk./Jurnal Rekayasa Mesin

p-ISSN: 1411-6863, e-ISSN: 2540-7678

Vol.15|No.3|229-236|Desember|2020

d.Buka katuppengisapan air laut dan katup air got perlahan-lahan sampai akhirnya katup pengisapan air got terbuka penuh dan katup air laut tertutup.

e.Selama proses pemisahan pada OWS berlangsung, perhatikan lampu yang terdapat pada tabung kedua (lampu indicator) bila menyala berarti tingkat minyak dalam tabung tinggi, buka katup pengeluaran untuk mengalirkan minyak ke sludge tank, setelah lampu padam tutup kembali katup pengeluaran. Sedang pada tabung pertama, pembukaan katup pengeluaran minyak diatur oleh solenoid yang mendapat sinyal dari Oil Level Sensor melalui Automatic Controller, lihat Gambar 3.

f. Selama air got yang dibuang memenuhi batas yang diijinkan maka solenoid valve pada pipa pengeluaran air buangan tetap terbuka. Dan bila kandungan minyak air buangan tinggi, solenoid valve akan bekerja setelah mendapat sinyal dari Oil Content Meter sehingga menutup saluran pengeluaran pada katup tiga arah (three away valve) yang mengakibatkan air buangan tersebut akan kembali lagi ke bilge tank untuk diproses ulang pada OWS, lihat Gambar 4.

\subsubsection{Langkah pembilasan}

a.Buka katup pengisapan air laut dan tutup katup pengisapan air got secara perlahan-lahan hingga katup pengisapan air got tertutup penuh dan katup pengisapan ait laut terbuka secukupnya. (tekanan dalam tabung $\left.0,5-0,7 \mathrm{~kg} / \mathrm{cm}^{2}\right)$.

b.Biarkan proses pembilasan dalam tabung berlangsung beberapa saat (15 mnt).

c.Stop Bilge pump.

d.Tutup katup pengisian air laut, katup antara tabung pertama dan kedua serta katup pembuangan keluar kapal.

e.Matikan Automatic Controller, Oil Content Meter dan Bilge pump.

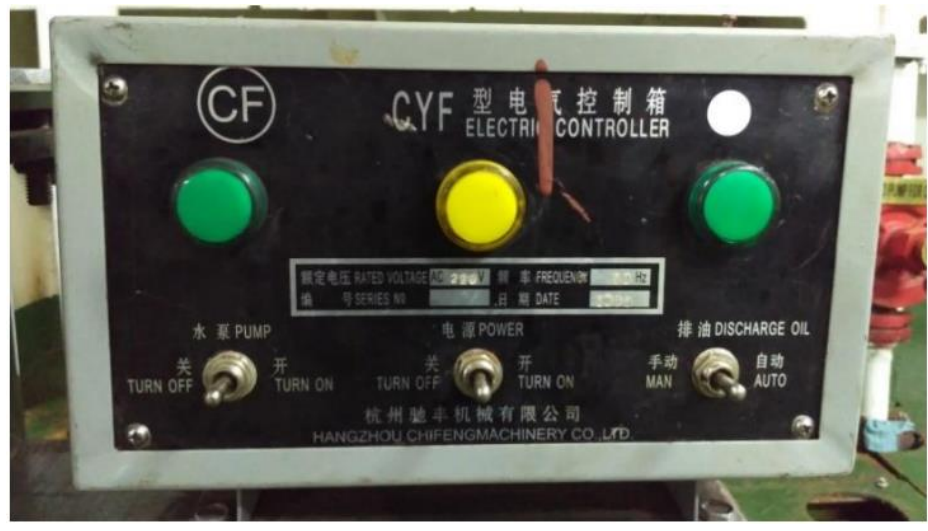

Gambar 3. Electric Controller OWS

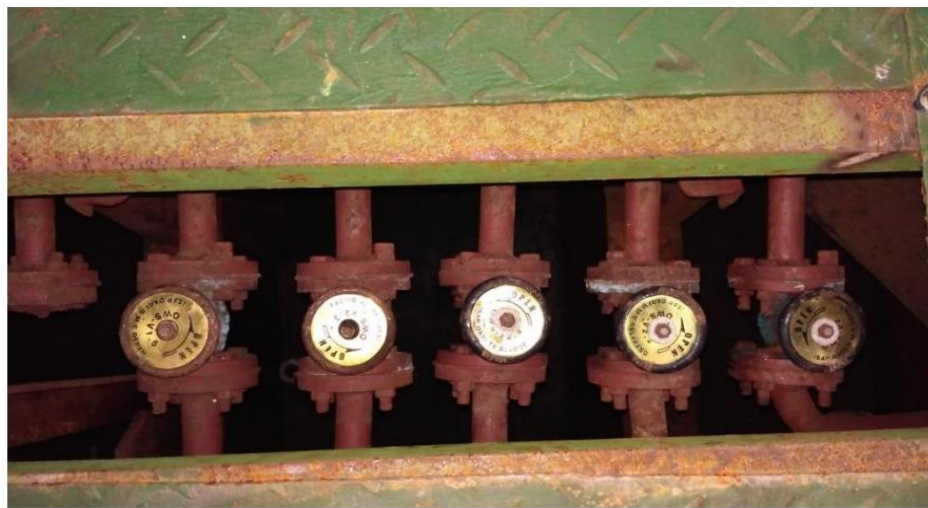

Gambar 4. Pipa Manifold line OWS 
Sulaiman dkk./Jurnal Rekayasa Mesin

p-ISSN: 1411-6863, e-ISSN: 2540-7678

Vol.15|No.3|229-236|Desember|2020

\subsection{Analisis permasalahan}

Perawatan terencana Oily water separator (OWS) yang tidak berjalan penyebabnya adalah kurangnya pemahaman cara merawat mesin Oily water separator (OWS) Sering di temukan para Anak Buah Kapal kurang mengikuti system perawatan yang semestinya di jalankan sesuai dengan petunjuk. Perawatan yang sedianya dilakukan secara rutin yang akan membantu kinerja Oily Water Separator bias bekerja secara maksimal, hal ini perlu sekiranya para anak buah kapal bias menjalankan perawatan secara berkala, beberapa hal penting misalnya (1) Melakukan pengetesan Oil Discharge Monitor alarm seminggu sekali. (2) Dilakukan pengoperasian Oily Water Separator setidaknya seminggu sekali dengan cara menggunakan media air laut atau di kenal dengan sea to sea, yang mana cara tersebut dimaksudkan guna membilas endapan lumpur yang menggenang atau menempel pada bagian-bagian column atau filter. (3) Perawatan berkala sekurang-kurangnya 6 bulan sekali dengan membuka column serta membersihkan saringan-saringan di dalam column - column tersebut. (4) Saringan saringan yang berhubungan dengan bilge system hendaknya di bersihkan secara terencana atau di bersihkan dengan melihat keadaan sebenarnya. (5) Anak Buah Kapal (ABK) mesin belum melaksanakan perawatan Standard Operating Procedure (SOP) dengan benar timbulnya kendala yang terjadi pada suatu mesin dikarenakan operator tidak melaksanakan Standard Operating Procedure. Untuk menunjang program kerja yang sesuai dengan aturan, maka dalam hal ini perlu standarisasi secara mendasar dan menyeluruh perihal penerapan Standard Operating Procedure dan berpedoman manual instruction bookatau PMS dari perusahaan. Hal ini sering kali para anak buah kapal kurang memperhatikan pada saat menjalankan oil water separator denganmembuka valve tidak sesuai dengan urutannya seperti membuka valve over boat yang mengakibatkan limbah minyak langsung terbuang kelaut pada hal kandungan minyak masih tinggi terbaca di atas $15 \mathrm{ppm}$. Dalam hal ini peran Chief Engineer / Senior Engineer pada saat memberikan instruksi atau latihan pengoperasian sangat diperlukan, Dan di tekankan kepada para anak buah kapal tentang pemahaman pencemaran air laut yang di sebabkan karena tidak maksimalnya kerja dari Oily water Separator

\subsection{Analisis pemecahan masalah}

Operator harus melaksanakan standard operating procedure (SOP) dengan benar timbulnya kendala yang terjadi pada suatu mesin dikarenakan operator tidak melaksanakan standar operating procedure. Untuk menunjang program kerja yang sesuai dengan aturan, maka dalam hal ini perlu standarisasi secara mendasar dan menyeluruh perihal penerapan standar operating procedure. Di dalam standar operating procedure. Operator dituntun / dipandu di saat melaksanakan program yang mengacu kepada buku petunjuk (instruction manual book). Beberapa hal yang harus dicermati dalam melaksanakan standar operating procedure, cermati dan mengerti fungsi dan cara kerja dari suatu mesin, laksanakan schedule dengan konsisten dan berkesinambungan. Setelah penerapan standarisasi / standar operating procedure dimengerti dan dipahami oleh para operator makadapat dilaksanakan dengan hasil baik. Tidak berfungsinya oil discharge monitoring (ODM) yang mengakibatkan pencemaran laut pemecahannya adalah adanya perawatan pada sensor oil content meter sebelum dan sesudah menjalankan oily water separator tentunya harus selalu dilakukan pembilasan dengan air tawar terhadap ruang pemisah pertama dan kedua serta sensor yang terdapat pada oil content meter. Hal ini selain untuk mencegah terjadinya karat juga dapat mencegah melekatnya partikel minyak pada sensor, yang jika terjadi secara terus menerus akan mengakibatkan sensor selalu membaca kadar minyak dalam jumlah yang tinggi. Jika hal ini terjadi maka kinerja dari oily water separator tidak tercapai karena oil water separator tidak akan melakukan proses pemisahan secara maksimal Karena hanya akan terjadi sirkulasi air got di kamar mesin. Beberapa cara perawatan pada oil content meter antara lain (1) Secara rutin minimal seminggu diadakan pembersihan 
Sulaiman dkk./Jurnal Rekayasa Mesin p-ISSN: 1411-6863, e-ISSN: 2540-7678

Vol.15|No.3|229-236|Desember|2020

dan pengetesan pada alat sensor tersebut. (2) Melakukan pengetesan alarm ppm setiap seminggu sekali baik dengan cara manual seperti tersebut diatas ataupun dengan cara menyeting pada alat Oil Content Meter tersebut sesuai dengan petunjuk.

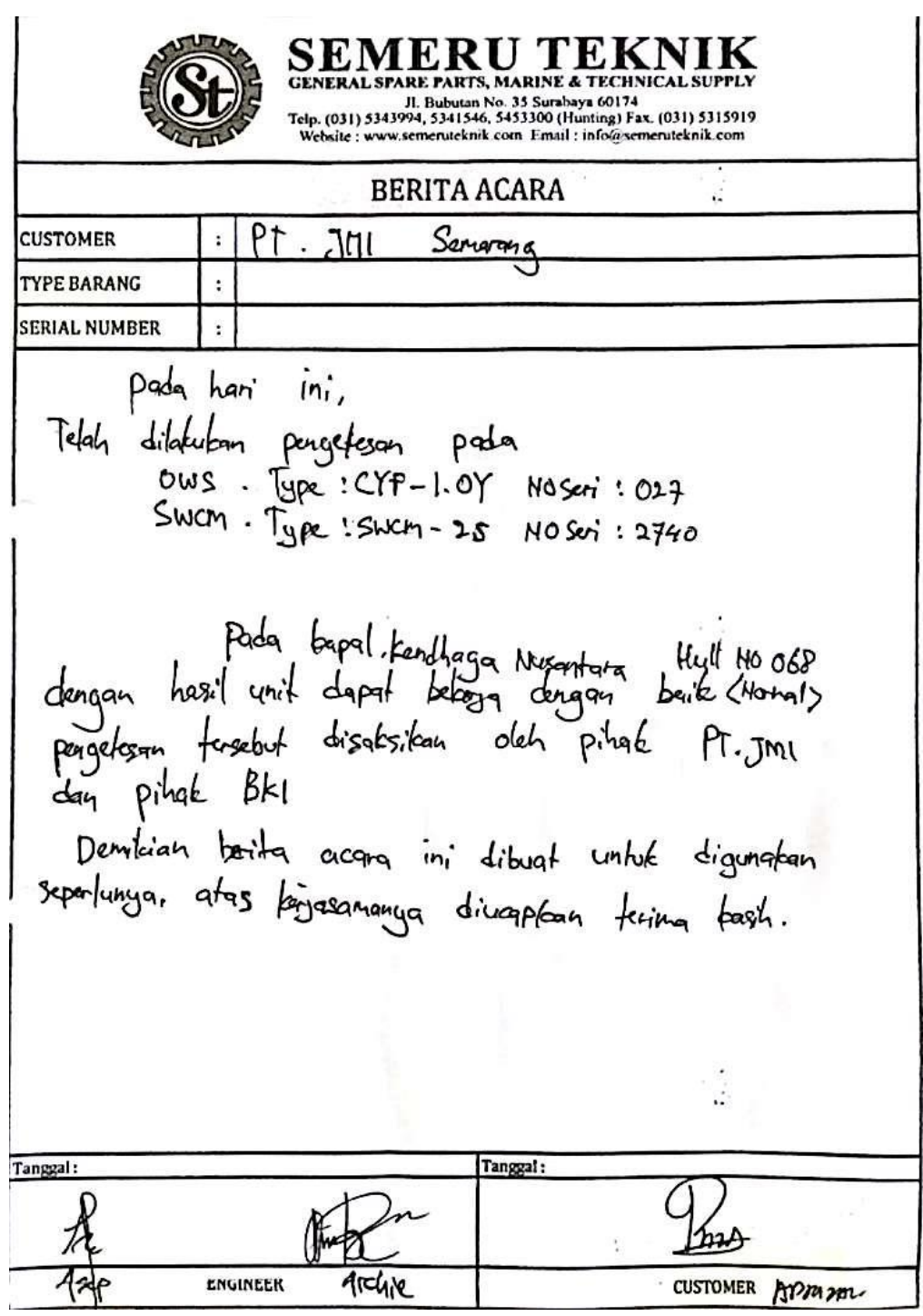

Gambar 5. Hasil Commisioning OWS

\section{Kesimpulan}

Kurang maksimalnya proses kinerja mesin oily water separator disebabkan oleh kurangnya familiarisasi tentang cara pengoperasian mesin oil water separator pada saat serah terima kapal dan pada saat pengoperasian oily water separator anak buah kapal sebagai operator belum melaksanakan standar operating procedure dengan baik dan benar. Selain itu tidak berfungsinya oil discharge monitoring pada sensor oil content meter yang kurang perawatannya, serta pengaturan oil content meter yang tidak sesuai dengan peraturan dari MARPOL Annex 1 (15 ppm).

\section{Daftar Pustaka}

[1] MARPOL 73/78 to Enter into Force on 2 October 1983. Environmentalist. 1983;3(1):58-9.

[2] Carpenter A. Oil pollution in the North Sea: the impact of governance measures on oil pollution over several decades. Hydrobiologia. 2019;845(1):109-27.

[3] Ariany Z, Khristyson SF, Mawardi II. Kajian Loading-Unloading Crude Oil Dari Platform Ke Fso Aberkha. Jurnal 
Sulaiman dkk./Jurnal Rekayasa Mesin p-ISSN: 1411-6863, e-ISSN: 2540-7678

Vol.15|No.3|229-236|Desember|2020

Inovtek Polbeng. 2019; Vol. 9(No. 1):54-65.

[4] Chitrakar P, Baawain MS, Sana A, Al-Mamun A. Current Status of Marine Pollution and Mitigation Strategies in Arid Region: A Detailed Review. Ocean Science Journal. 2019;54(3):317-48.

[5] Dobson NL. Competing Climate Change Responses: Reflections on EU Unilateral Regulation of International Transport Emissions in Light of Multilateral Developments. Netherlands International Law Review. 2020.

[6] Bulycheva E V, Krek A V, Kostianoy AG. Peculiarities of distribution of oil polution in the Southeastern Baltic by satellite data and in situ measurements. Oceanology. 2016;56(1):75-83.

[7] Ma N, McDowell BJ, Houser JB, Andrade MW, Heinz DE. Separation of Mill Scale from Flume Wastewater Using a Dynamic Separator Toward Zero Wastes in the Steel Hot-Rolling Process. Journal of Sustainable Metallurgy. 2019;5(1):97-106.

[8] Wang J, Maw MM, Yu X, Dai B, Wang G, Jiang Z. Applications and perspectives on microfluidic technologies in ships and marine engineering: a review. Microfluidics and Nanofluidics. 2017;21(3):39.

[9] Gulyaeva LA, Lobashova MM, Mitusova TN, Shmel'kova OI, Khavkin VA, Nikul'shin PA. Production of Low Sulfur Marine Fuel. Chemistry and Technology of Fuels and Oils. 2020;55(6):704-11.

[10] Utomo B, Khristyson SF, Pasaribu AP. Analisa Perawatan Lambung Single Mooring Buoy (Sbm) Sebagai Sarana Penunjang Alur Pelayaran Transportasi Laut. Jurnal Inovtek Polbeng. 2020;Vol. 10(no. 1):12-9.

[11] Darvish Sarvestani A, Moazami Goodarzi A, Hadipour A. Integrated asset management: a case study of technical and economic optimization of surface and well facilities. Petroleum Science. 2019;16(5):1221-36.

[12] Shojaeefard MH, Khaneshan VM, Ehteram MA, Akbari M, Allymehr E. Taguchi optimization of micron sized lubricant oil droplet deposition on a hot plate. Journal of Mechanical Science and Technology. 2015;29(8):327785.

[13] Zhang J, Yuan H, Zhao J, Mei N. Theoretical and Experimental Investigations of Identifying the Ingredients of an Oil-Water Mixture Based on a Characteristic Fluid Inverse Problem. International Journal of Thermophysics. 2016;37(12):128.

[14] Zetterdahl M, Salo K, Fridell E, Sjöblom J. Impact of aromatic concentration in marine fuels on particle emissions. Journal of Marine Science and Application. 2017;16(3):352-61.

[15] Sagdatullin M. Development of Mathematical Model and Technological Process Flow Diagram of Delivery of Reagent in Initial Treatment of Oil Production of Wells in Separator Tanks. Chemical and Petroleum Engineering. 2020;55(11):884-7.

[16] Höfer T. Review articles: Tankships in the marine environment. Environmental Science and Pollution Research. 1999;6(2):107-14.

[17] Nasrazadani S, Akhtar MA, Patel A, Ezell C. Failure Analysis of API 5L (Grade B) Oil Field Separator Flowline Pipe. Journal of Failure Analysis and Prevention. 2018;18(4):721-6.

[18] Cogliolo A. Sustainable shipping green innovation for the marine industry. Rendiconti Lincei. 2015;26(1):65-72.

[19] Ganul MN, Kuchin NL, Sergeev I V. Investigation of the development of radioactive pollution of sea water occurring when a nuclear-powered ship sinks in the open sea. Atomic Energy. 1996;81(4):722-7. 